\title{
Painless isolated spontaneous dissection of the superior mesenteric artery
}

\author{
Yukihiro Otaka (D) , ${ }^{1,2}$ Masakazu Yamaguchi, ${ }^{1}$ Nobuyoshi Ishiyama, ${ }^{1}$ \\ Keiko Kawai-Kowase ${ }^{2}$
}

${ }^{1}$ General Internal Medicine, Hidaka-kai Hidaka Hospital, Takasaki, Gunma, Japan ${ }^{2}$ Department of General Medicine, Gunma University Graduate School of Medicine, Maebashi, Gunma, Japan

Correspondence to Professor Keiko Kawai-Kowase; kowasek@gunma-u.ac.jp

Accepted 14 December 2021

\section{DESCRIPTION}

A man in his early 60 s with a history of type 2 diabetes mellitus for more than 10 years and hypertension was admitted to the emergency room due to a sudden onset of nausea and vomiting from 2 days. On admission, he was haemodynamically stable, and no abdominal bruit was appreciated. Laboratory tests showed a slight increase in white blood cell count and $\mathrm{C}$ reactive protein, but no other abnormalities in biochemistry and coagulation ability were observed. Contrast-enhanced CT revealed an isolated dissection of the superior mesenteric artery (SMA) without aortic dissection or aneurysm (figure 1). There was an increase in SMA diameter $(17 \mathrm{~mm}$, maximum) extending to a length of $33 \mathrm{~mm}$. Partial segmental contrast defect on the intimal flap was detected at $22 \mathrm{~mm}$ from the root of the SMA, suggesting an entry of the dissection. The true lumen was smaller due to compression by the false lumen. Both true and false lumens were contrast-enhanced and appeared to be cul-de-sac-shaped. This suggests the false lumen had an entry but not a re-entry and is classified as type 2 according to the original Sakamoto's classification. The intimal flap of the SMA was identified by both CT scan and grey-scale ultrasound imaging (figure 2). On colour Doppler imaging, a swirling pattern was seen with the 'yin-yang sign' of the false lumen (figure 2), showing a to and fro motion of the false luminal blood flow. There was no suggestive sign of complete bowel ischaemia through the initial examinations, nevertheless, acute localised dissection of the SMA and a subsequent truncated upper bowel ischaemia possibly caused his primary symptoms such as nausea and

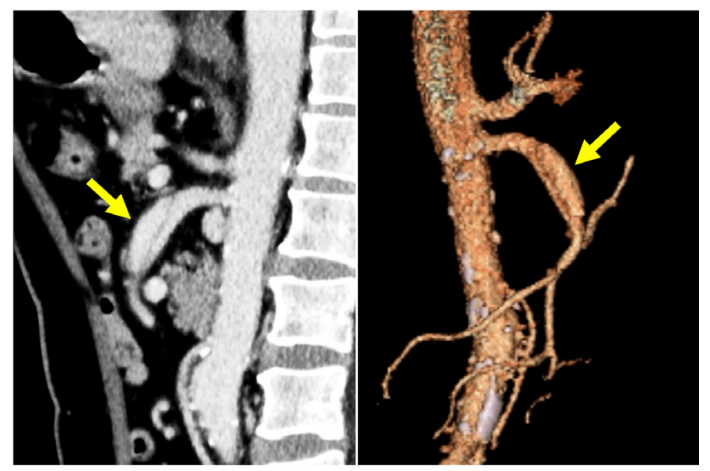

Figure 1 Sagittal contrast-enhanced CT of the abdomen showing isolated dissection of the superior mesenteric artery with enhancements in both true and false lumens (arrows). Three-dimensional CT angiography (right) confirming the presence of a localised dissection and the peripheral blood flow.

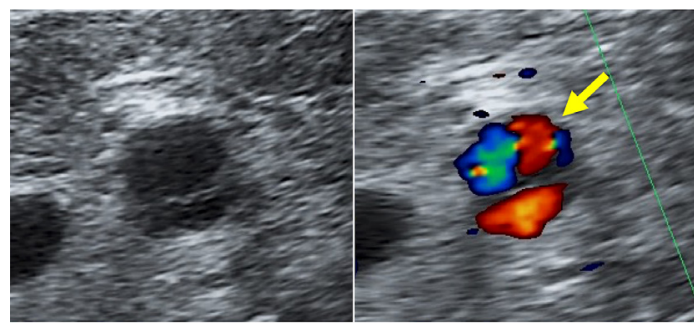

Figure 2 Axial ultrasound imaging of the superior mesenteric artery showing an enlarged false lumen, an intimal flap (left) and to and fro motion of blood flow on colour Doppler imaging (right, arrow).

vomiting. A transient ischaemia of the inferior pancreaticoduodenal artery, a branch of the SMA, may cause acute upper abdominal symptoms localised on the ascending and inferior parts of the duodenum.

The patient was treated conservatively with fasting and oral antihypertensive therapy. His nausea and vomiting completely disappeared on day 3 , and oral intake was resumed. He was symptom-free within 6 months after discharge and the follow-up CT revealed partial remodelling of the patent false lumen.

In general, the most common symptom was abdominal pain, followed by nausea and vomiting, haematochezia and diarrhoea. ${ }^{2}$ In the previous case series, asymptomatic and painless isolated spontaneous dissection of the SMA were reported, accounting for 6.7\%$35.7 \%$ and $19.7 \%$ of the total cases of SMA dissection, respectively. ${ }^{34}$ Due to a long history of diabetes in the present case, painless dissection with only digestive symptoms seemed to have occurred based on diabetic neuropathy as one of its chronic complications. Most cases without intestinal ischaemia are treated with conservative methods, ie, no endovascular or surgical interventions are performed. ${ }^{5-7}$ Though conservative treatment includes mainly intestinal rest by fasting, blood pressure control, anticoagulant, antiplatelet and

\section{Learning points}

- Isolated spontaneous dissection of the superior mesenteric artery (SMA) is relatively rare; nevertheless, it is still an important differential of acute abdomen.

- Asymptomatic or painless cases of the SMA dissociation are uncommon, but they do exist. These rare conditions may be overlooked in cases of hypaesthesia associated with metabolic diseases such as diabetes mellitus. 
thrombolytic therapies, there is no clear, rigid protocol for the treatment of SMA dissection.

Acknowledgements The authors thank Dr Wataru Tatsuishi (Cardiovascular Surgery, Hidaka-kai Heisei Hidaka Clinic), Dr Ayaka Hirota, Dr Shoma Yamauchi, Dr Yuki Kuribara and Dr Kota Otachi (General Internal Medicine, Hidaka Hospital) for their aid in patient management. We also thank Enago (www.enago.jp) for the English language review.

Contributors $\mathrm{YO}$ and MY drafted the manuscript and obtained the pictures. YO, MY and NI contributed to patient care. NI and KK-K supervised the study and critically reviewed the manuscript. All authors wrote, proofread and approved the final version of manuscript.

Funding The authors have not declared a specific grant for this research from any funding agency in the public, commercial or not-for-profit sectors.

Competing interests None declared.

Patient consent for publication Consent obtained directly from patient(s).

Provenance and peer review Not commissioned; externally peer reviewed.

Case reports provide a valuable learning resource for the scientific community and can indicate areas of interest for future research. They should not be used in isolation to guide treatment choices or public health policy.

\section{ORCID iD}

Yukihiro Otaka http://orcid.org/0000-0002-9162-7188

\section{REFERENCES}

1 Sakamoto I, Ogawa Y, Sueyoshi E, et al. Imaging appearances and management of isolated spontaneous dissection of the superior mesenteric artery. Eur J Radiol 2007:64:103-10.

2 Kimura Y, Kato T, Inoko M. Outcomes of treatment strategies for isolated spontaneous dissection of the superior mesenteric artery: a systematic review. Ann Vasc Surg 2018;47:284-90.

3 Satokawa H, Takase S, Seto Y, et al. Management strategy of isolated spontaneous dissection of the superior mesenteric artery. Ann Vasc Dis 2014;7:232-8.

4 Luan JY, Guan X, Li X, et al. Isolated superior mesenteric artery dissection in China. J Vasc Surg 2016;63:530-6.

5 Jia Z, Tu J, Jiang G. The classification and management strategy of spontaneous isolated superior mesenteric artery dissection. Korean Circ J 2017:47:425-31.

6 Wang J, He Y, Zhao J, et al. Systematic review and meta-analysis of current evidence in spontaneous isolated celiac and superior mesenteric artery dissection. J Vasc Surg 2018;68:1228-40

7 Ullah W, Mukhtar M, Abdullah HM, et al. Diagnosis and management of isolated superior mesenteric artery dissection: a systematic review and meta-analysis. Korean Circ J 2019:49:400-18.

Copyright 2021 BMJ Publishing Group. All rights reserved. For permission to reuse any of this content visit

https://www.bmj.com/company/products-services/rights-and-licensing/permissions/

BMJ Case Report Fellows may re-use this article for personal use and teaching without any further permission.

Become a Fellow of BMJ Case Reports today and you can:

Submit as many cases as you like

Enjoy fast sympathetic peer review and rapid publication of accepted articles

- Access all the published articles

Re-use any of the published material for personal use and teaching without further permission

Customer Service

If you have any further queries about your subscription, please contact our customer services team on +44 (0) 2071111105 or via email at support@bmj.com.

Visit casereports.bmj.com for more articles like this and to become a Fellow 